Check for updates

Cite this: J. Mater. Chem. C, 2021 , 9, 6528

Received 29th January 2021, Accepted 30th April 2021

DOI: $10.1039 / \mathrm{d} 1 \mathrm{tc} 00443 \mathrm{c}$

rsc.li/materials-c

\section{Liquid-crystalline TADF materials based on substituted carbazoles and terephthalonitrile $\uparrow$}

\author{
Alfiya F. Suleymanova, (D) a Marsel Z. Shafikov, (D) ${ }^{\text {bc }}$ Adrian C. Whitwood, (D) a \\ Rafat Czerwieniec (D)*b and Duncan W. Bruce (1)*a \\ By functionalising 2,5-di( $N, N^{\prime}$-carbazolyl)terephthalonitrile or 2,3,5,6-tetra( $N, N^{\prime}$-carbazolyl)terephthalonitrile \\ with alkoxy chains located on the carbazole moiety, a family of materials is realised, all of which show a \\ TADF response and two of which are also liquid crystalline.
}

\section{Introduction}

There is great interest in luminescent liquid crystals as multifunctional materials, as they combine emissive properties with the ability to self-organise over extended length scales. This combination of properties suggests potential applications in the general field of electronic devices, such as polarised emitters, ${ }^{1,2}$ organic field-effect transistors (OFETs), ${ }^{3,4}$ organic photovoltaic devices ${ }^{5,6}$ and organic light emitting diodes, OLEDs. ${ }^{7}$

Because of their ability to harvest $100 \%$ of the excitons produced in the OLED device, phosphorescent materials are much more effective emitters comparing to fluorescence equivalents and those based on iridium(III) in particular are used successfully in the current generation of commercial OLED displays. ${ }^{8,9}$ However, more recently there has been increasing interest in a new family of emissive materials based on fluorescence which, in common with phosphorescent materials, can utilise $100 \%$ of device excitons. ${ }^{10}$ This is possible when the lowest excited singlet and triplet states, $S_{1}$ and $T_{1}$, are close in energy. When the $\mathrm{S}_{1}-\mathrm{T}_{1}$ separation is sufficiently small, the singlet state can be populated thermally from the lowerlying triplet state generated in course of electroluminescent excitation in the OLED. Thus, thermally activated delayed fluorescence, TADF, is observed. The small separation of the

\footnotetext{
${ }^{a}$ Department of Chemistry, University of York, Heslington, YORK YO10 5DD, UK. E-mail: duncan.bruce@york.ac.uk; Tel:+44 1904324085

${ }^{b}$ Institut für Physikalische Chemie Universität Regensburg, Universitätsstrasse 31, Regensburg 93053, Germany. E-mail: rafal.czerwieniec@chemie.uni-regensburg.de; Tel: +499419434463

${ }^{c}$ Ural Federal University, Mira 19, Ekaterinburg, 620002, Russia

$\dagger$ Electronic supplementary information (ESI) available. CCDC 2056911 and 2056912. For ESI and crystallographic data in CIF or other electronic format see DOI: $10.1039 / \mathrm{d} 1 \mathrm{tc} 00443 \mathrm{c}$
}

$\mathrm{S}_{1}$ and $\mathrm{T}_{1}$ states can be achieved when the HOMO and LUMO orbitals are separated significantly in space. In such a case, the exchange energy is small and the states resulting from the HOMO $\rightarrow$ LUMO excitation are close in energy. The ability to realise high electroluminescence efficiency then no longer relies on the incorporation of a heavy metal to facilitate spinorbit coupling.

However, while there has been interest in the design and synthesis of liquid-crystalline materials that are either phosphorescent or emit through conventional fluorescence mechanisms, to the best of our knowledge there are currently no examples of liquid-crystalline TADF materials.

Pioneered by Adachi and co-workers, ${ }^{11}$ the use of carbazole donors with terephthalonitrile (1,4-dicyanobenzene) acceptors represents an archetypal class of purely organic TADF materials. In these compounds, the HOMO is essentially centred at the carbazole moieties whereas the LUMO is localised on the dicyanobenzene moiety. The separation of the frontier orbitals arises as the donor and acceptor rings are essentially orthogonal to each other.

As demonstrated by Giroud-Godquin ${ }^{12}$ and by Swager, ${ }^{13,14}$ and then later used by ourselves with octahedral iridium(III) complexes, ${ }^{15,16}$ judicious functionalisation of the periphery of a more three-dimensional molecule by flexible alkyl chains can generate an anisotropic motif capable of being stabilised in a liquid-crystal phase. Indeed, fullerenes can also be made liquid crystalline ${ }^{17}$ Therefore, using this general approach, we generated a family of four related compounds $(\mathbf{3 a}, \mathbf{3} \mathbf{b}, \mathbf{4 a}, \mathbf{4} \mathbf{b})$ whose preparation and formulae are shown in Scheme 1. The mono(1a) or di-(1b) alkoxyphenyl dioxaborolanes were obtained directly from the corresponding alkoxybromobenzene and were then reacted with 3,6-dibromocarbazole using a Suzuki-Miyaura protocol to give the substituted carbazoles 2 . Target compounds 3 and $\mathbf{4}$ were then obtained in a nucleophilic substitution reaction 


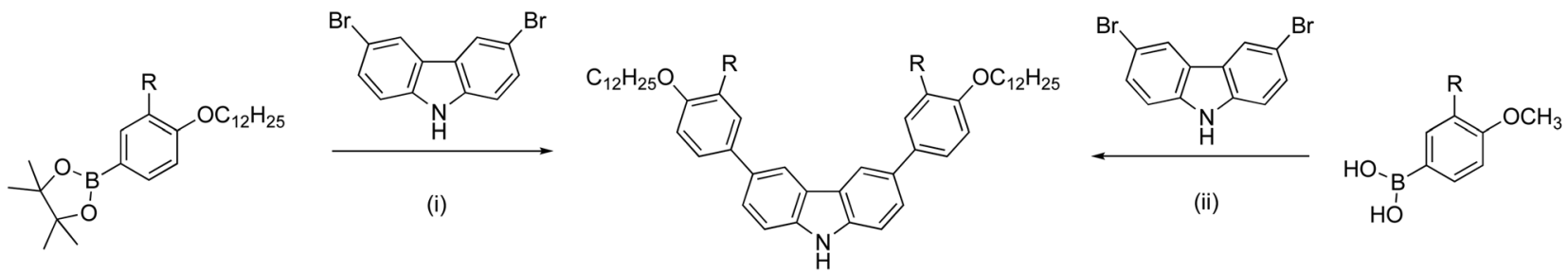

1a: $\mathrm{R}=\mathrm{H}$

1b: $\mathrm{R}=\mathrm{OC}_{12} \mathrm{H}_{25}$
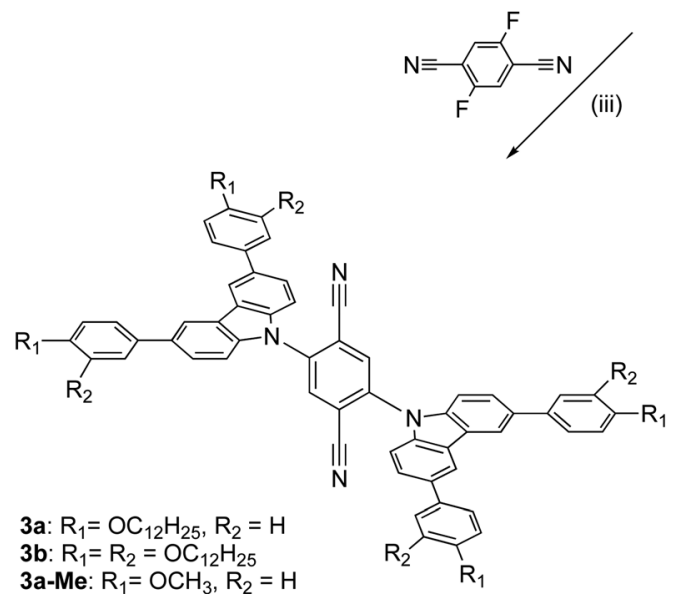

2a: $\mathrm{R}=\mathrm{H}$

2b: $\mathrm{R}=\mathrm{OC}_{12} \mathrm{H}_{25}$

2a-Me: $\mathrm{R}=\mathrm{H}$

2b-Me: $\mathrm{R}=\mathrm{OCH}_{3}$

3b-Me: $\mathrm{R}_{1}=\mathrm{R}_{2}=\mathrm{OCH} 3$

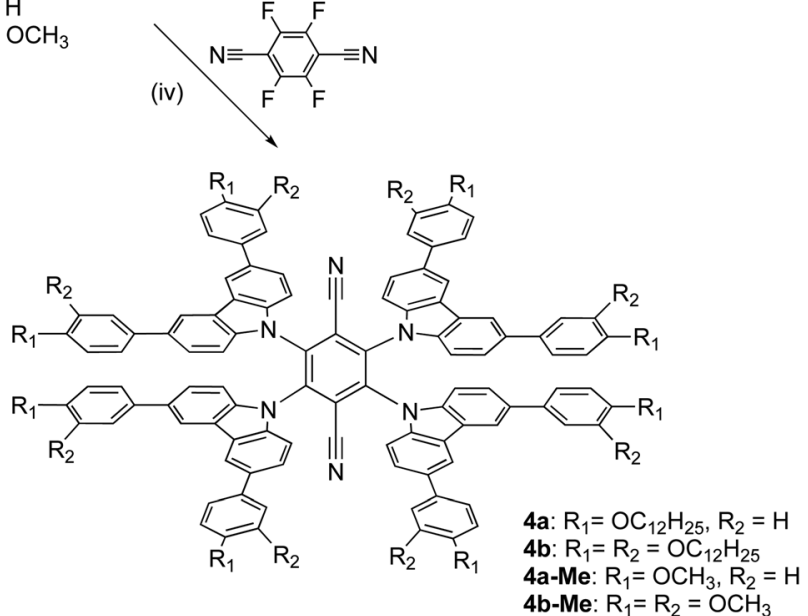

Scheme 1 Synthetic route to the target products 3 and 4 . Conditions: (i) and (ii) $\mathrm{K}_{2} \mathrm{CO}_{3}\left(10 \mathrm{~mol}\right.$ equiv.), [Pd$\left(\mathrm{Pd}_{3}(\mathrm{OAc})_{6}\right](0.2 \mathrm{~mol}$ equiv.), $\mathrm{S}$ - $\mathrm{Phos}$ (0.4 mol equiv.), toluene/ethanol/water, $80{ }^{\circ} \mathrm{C}, 24-48 \mathrm{~h}$; (III) and (iv) $\mathrm{NaH}$ (6 mol equiv.), DMF or THF, $75{ }^{\circ} \mathrm{C}, 4 \mathrm{~h}$.

with 2,5-difluoroterephthalonitrile or 2,3,5,6-tetrafluoroterephthalonitrile, respectively. Full details are found in the ESI. $\dagger$

It was possible to obtain single crystals of the methoxy analogues of $\mathbf{3 b}$ and $\mathbf{4 b}$ (labelled $3 \mathbf{b}$-Me and $\mathbf{4 b}-\mathbf{M e}$, respectively) and their structures were determined using X-ray methods; the data are recorded in Table $\mathrm{S} 1$ (ESI $\dagger$ ), while the structures are shown as Chart 1 . Analysis of the structure of $\mathbf{3 b} \mathbf{b}$-Me shows that the plane described by the central phenyl ring of the terephthalonitrile subtends an angle of $54.84^{\circ}$ to a plane described by the five atoms in the pyrrolic ring of the carbazole. This is somewhat smaller than that found in related materials functionalised with more carbazole groups, reflecting the lower steric crowding. In terms of intermolecular interactions, there is a distance of $3.985 \AA$ between the planes of phenyl groups bearing the methoxy groups (Fig. S1, ESI $\dagger$ ), but no short contacts between carbazole units. ${ }^{18}$

In the structure of $\mathbf{4 b} \mathbf{b}-\mathbf{M e}$, the plane described by the central phenyl ring of the terephthalonitrile subtends a somewhat larger angle of $63.48 \pm 0.05^{\circ}$ to the planes described by the five atoms in the pyrrolic ring of the carbazole. Steric effects open this angle up compared to that found in $\mathbf{4 a - M e}$ and indeed, the larger angle is similar values to those found in related structures described by Etherington et al. ${ }^{18}$ Also in common with their observations, a close intermolecular ringring contact of about $3.9 \AA$ is found between carbazole phenyl rings (Chart 1b) and an illustration of the overlap is shown in Chart 1c. Such interactions were proposed as the origin of changes in emission characteristics, sometimes also as a function of concentration in the emissive layer, in the solid state and devices on the basis of the existence of persistent dimer states.

\section{Liquid-crystalline properties}

The thermal properties of compounds $\mathbf{3}$ and $\mathbf{4}$ were first determined by polarised optical microscopy, which showed that neither 3a nor $4 \mathbf{a}$ was a liquid crystal, each simply melting to give an isotropic fluid at 242 and $249{ }^{\circ} \mathrm{C}$, respectively. Being (short-chain) methoxy derivatives, neither 3b-Me nor 4b-Me shows liquid crystal properties. However, for $\mathbf{3 b}$ and $\mathbf{4 b}$ the situation was different, and both were found to show a columnar hexagonal $\left(\mathrm{Col}_{h}\right)$ mesophase; the observations are the same for both compounds. Placing the as-obtained material on the microscope slide, it was found to be rather viscous with the viscosity decreasing as the temperature increased and while there was an overall birefringence to the sample, there was no discernible texture to help identify the phase. However, at $181{ }^{\circ} \mathrm{C}(3 \mathbf{b})$ or $191{ }^{\circ} \mathrm{C}(\mathbf{4 b})$ the birefringent fluid gave way to an isotropic fluid which, on cooling developed well-defined optical textures as shown in Fig. 1a and b, both being characteristic of a $\mathrm{Col}_{h}$ mesophase. The transitions were detected also by DSC (Fig. 1c and $\mathrm{d}$ )

To confirm the symmetry of the observed mesophases, small-angle X-ray scattering (SAXS) measurements were performed for both compounds and the diffraction patterns are shown in Fig. 2. Compound $\mathbf{3 b}$ showed a strong, low-angle 


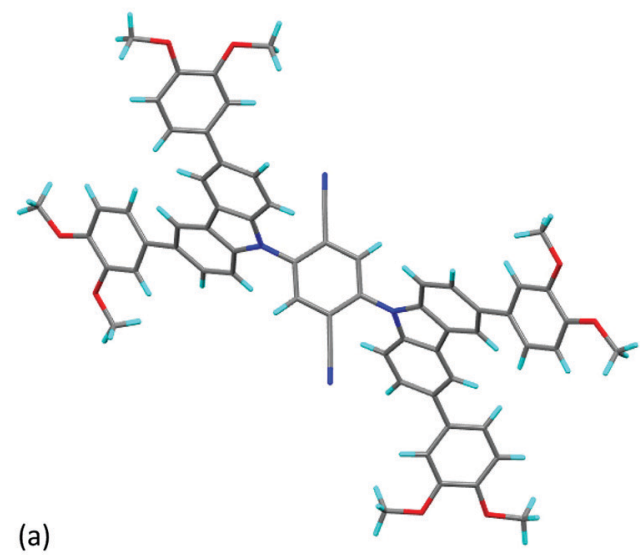

(a)

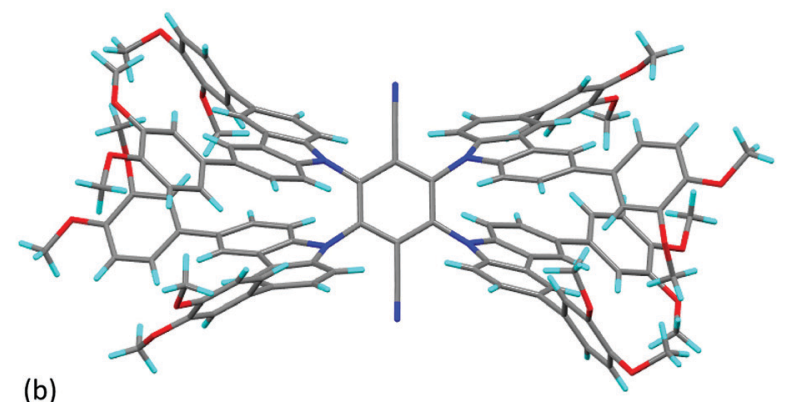

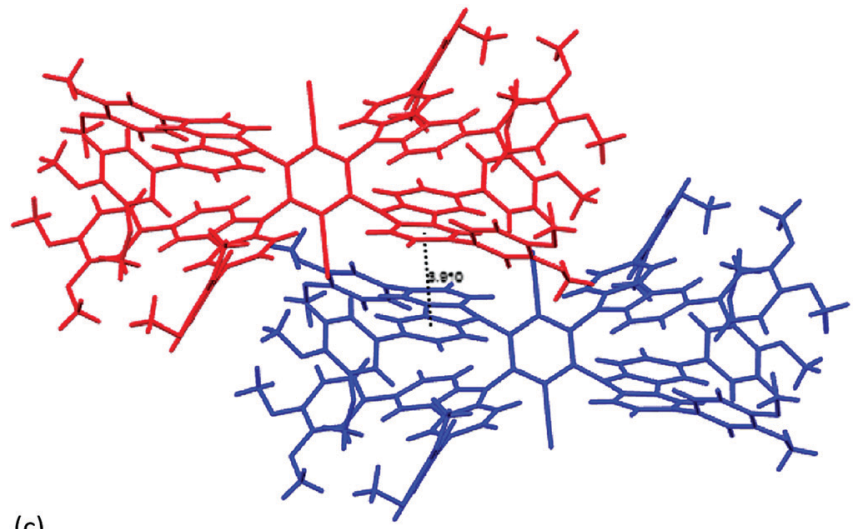

(c)

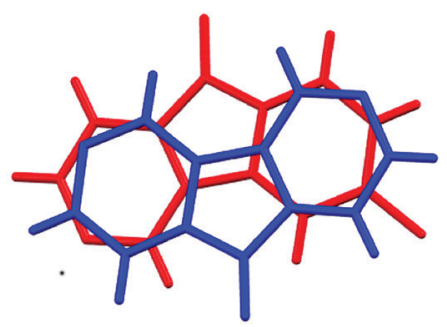

(d)

Chart 1 (a) Molecular structure of compound $3 \mathbf{b}-\mathbf{M e}$; (b); molecular structure of compound $\mathbf{4 b}-\mathbf{M e}$ (c) figure showing the close approach of two molecules of $\mathbf{4 b - M e}$ in the solid state giving rise to the intermolecular ring-ring separation of $3.910 \AA$ (different molecules color-coded for ease of observation); (d) figure to show the detail of the overlap of the carbazole ring systems.

(10) reflection at $2 \theta=2.52^{\circ}$ (Fig. 2a) corresponding to a $d$-spacing of $35 \AA$ and a lattice (a) parameter of $40.4 \AA$ A. Much weaker reflections at $2 \theta=4.33^{\circ}$ and $4.93^{\circ}$ were assigned as the corresponding (11) and (20) reflections, confirming hexagonal symmetry. For compound $\mathbf{4 b}$, the strong reflection was found at a very similar angle $\left(2 \theta=2.79^{\circ}\right.$, Fig. $\left.2 \mathrm{~b}\right)$, although higher-order reflections were not readily evident. The assignment of $\mathbf{4} \mathbf{b}$ as showing a $\mathrm{Col}_{\mathrm{h}}$ phase was confirmed as it was found to be continuously miscible with $\mathbf{3 b}$ (Fig. S2, ESI $\dagger$ ). From the single crystal structure of $\mathbf{4 b}-\mathbf{M e}$ and from literature data for all-trans $\mathrm{C} 12$ chains, it is possible to estimate the length of $\mathbf{3 b}$ and $\mathbf{4 b}$ to be about $53 \AA$, which is significantly greater than the lattice parameter evaluated for $\mathbf{3 b}(\approx 40 \AA)$ or $\mathbf{4 b}(\approx 36 \AA)$, suggesting some tilting of the molecular units within the columns. ${ }^{19}$

\section{Photophysical properties}

UV-Vis absorption spectra of compounds $\mathbf{3 a}, \mathbf{3 b}, \mathbf{4 a}$, and $\mathbf{4} \mathbf{b}$ reveal distinct, low-energy absorption bands due to chargetransfer transitions. Respective band maxima are, for example, $440 \mathrm{~nm}$ for $\mathbf{3 a}$ and $\mathbf{3 b}$ and $510 \mathrm{~nm}$ for $\mathbf{4 a}$ and $\mathbf{4 b}$, respectively. (Fig. 3 and Fig. S3 in ESI $\dagger$ ). The charge-transfer character of the excited states, resulting from an electron density shift from carbazole moieties to terephthalonitrile, is in accordance with literature data for analogous carbazole-cyanobenzenes ${ }^{11}$ and is also consistent with the results from TD-DFT calculations (below).

All of the compounds are luminescent at ambient temperature both as dilute solutions in organic solvents and as solid samples and their emission spectra recorded in toluene are shown in Fig. 4. The band maxima, decay times, and quantum yields are listed in Table 1.

The emission bands are broad and structureless, reflecting the strongly charge-transfer character of the respective electronic transitions. Owing to the measured decay times on the order of several nanoseconds and partial spectral overlap with the lowestenergy absorption features, the emissions are identified as being dominated by prompt fluorescence $\left(S_{1} \rightarrow S_{0}\right)$. However, in the decay profiles, longer-lived components with a decay time of several hundred ns $(\mathbf{4 a}, \mathbf{4 b})$ up to 3.5 and $5.5 \mu \mathrm{s}$ (3b and $3 \mathbf{a}$, respectively) are present. The longer-lived emission component, which is on a $\mu$ s timescale and originates from the $T_{1}$ state, is the most evident in compound 3a (Fig. 5) and accounts for around $10 \%$ of the net intensity. Intrinsic phosphorescence (radiative transition $\mathrm{T}_{1} \rightarrow \mathrm{S}_{0}$ ) lifetimes for organic compounds normally amount to hundreds of milliseconds up to seconds. The $\mathrm{T}_{1}$ lifetime observed here, however, which is in the range $<1 \mu \mathrm{s}$ to $5.5 \mu \mathrm{s}$ is much shorter and points to another relaxation mechanism, which, at ambient temperature, is most probably TADF. This assignment results straightforwardly from the analogy to related carbazole-terephthalonitrile derivatives, for which 

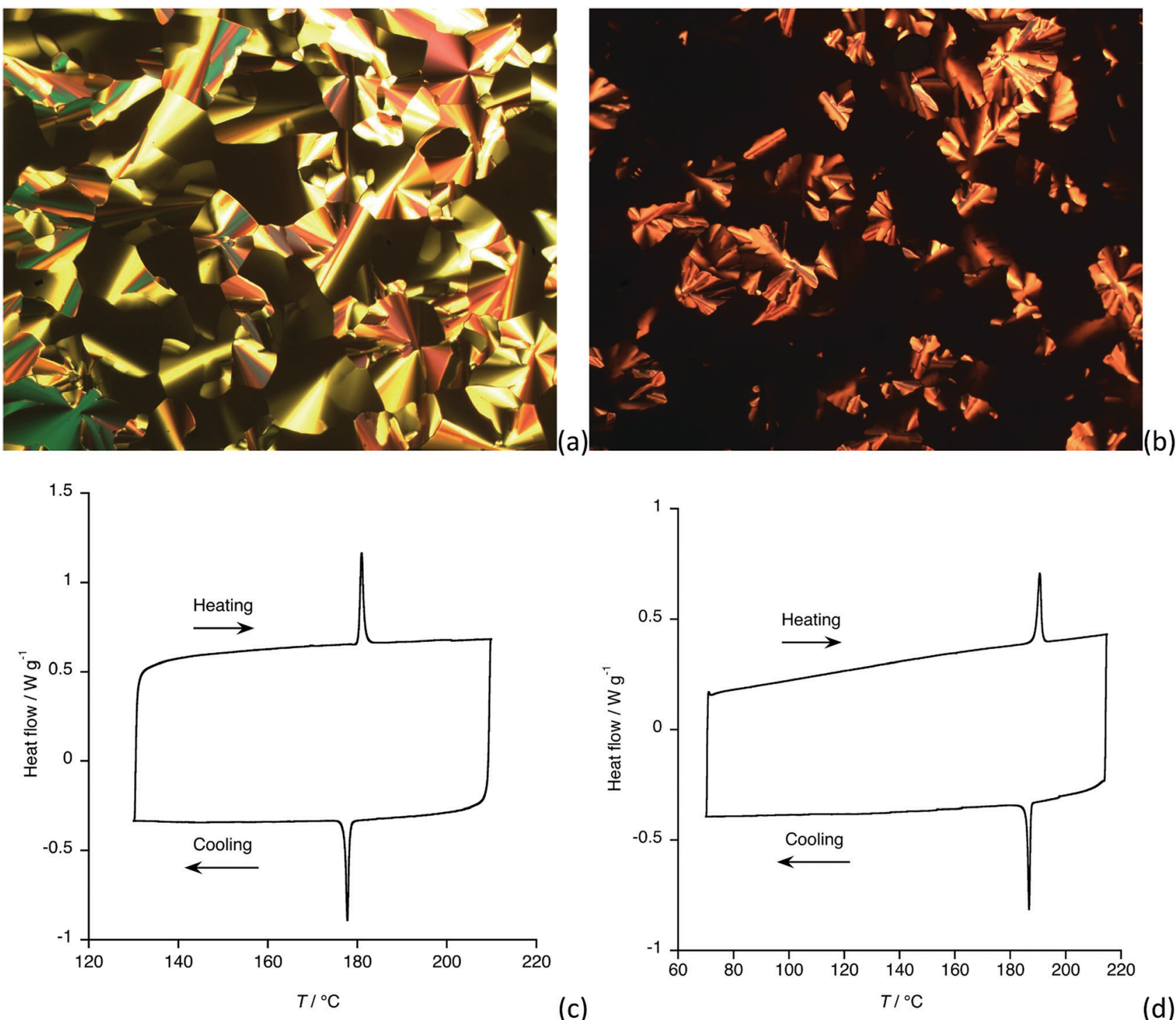

(d)

Fig. 1 Polarising optical microscopy images: (a) compound $\mathbf{3 b}$ at $177^{\circ} \mathrm{C}$ on cooling; (b) compound $\mathbf{4 b}$ at $186{ }^{\circ} \mathrm{C}$ on cooling. DSC traces (second heat and second cool, scan rate of $5{ }^{\circ} \mathrm{C} \mathrm{min}^{-1}$ ): (c) compound $\mathbf{3 b}$; (d) compound $\mathbf{4 b}$.

significant TADF was reported, ${ }^{11}$ and results of quantum chemical computations (below), predicting small $\mathrm{S}_{1}-\mathrm{T}_{1}$ energy separations of less than $0.1 \mathrm{eV}$ - a prerequisite for efficient TADF.

The energy of the emitting singlet state depends on both the number of alkoxy groups attached to each carbazole moiety (two in compounds $\mathbf{3 a}$ and $\mathbf{4 a}$ and four in $\mathbf{3 b}$ and $\mathbf{4 b}$, respectively) and the number of carbazole moieties in the molecule (two in $\mathbf{3 a}$ and $\mathbf{3 b}$, and four in $\mathbf{4 a}$ and $\mathbf{4 b}$, respectively). Thus, the emission maximum of compound $\mathbf{3 a}$ with just two carbazoles bearing two alkoxy groups is $545 \mathrm{~nm}$ while the emission maximum of compound $\mathbf{4 b}$ with four carbazoles bearing four alkoxy groups is $620 \mathrm{~nm}$. The maxima of compounds $\mathbf{3 b}$ and $\mathbf{4 a}$ have intermediate values of 560 and $615 \mathrm{~nm}$, respectively and each alkoxy group increases the donor strength of the carbazole moiety, thus shifting the $S_{1}$ state to lower energy. Greater numbers of donor moieties in compounds $\mathbf{4 a}$ and $\mathbf{4 b}$ as compared to $\mathbf{3 a}$ and $\mathbf{3 b}$ increase the HOMO energy due to $\pi-\pi$ interactions between adjacent carbazoles (in ortho position one to another) and decreases the LUMO energy, probably as an effect of the larger angles between the planes of terephthalonitrile acceptor and the carbazole donor moieties and the concomitantly reduced LUMO delocalisation in $\mathbf{4 a}$ and $\mathbf{4 b}$. ( $c f$. Fig. S8, ESI $\dagger$ ) The other point of interest here is that while the effect of the addition of a methoxy group in the 4-position of the phenyl group is significant (e.g. $\lambda_{\mathrm{em}}=615 \mathrm{~nm}$ for $4 \mathrm{a}$ compared to $577 \mathrm{~nm}$ for the equivalent compound with no methoxy groups-3,6-diphenylcarbazole donor), ${ }^{11}$ addition of the second methoxy group further redshifts the emission by only $5 \mathrm{~nm}$ to $620 \mathrm{~nm}$ because the $\pi$ donor in the 3-position of the phenyl ring is not in conjugation with the carbazole.

The same trend found in solution is also observed for solid samples (Fig. S4 and Table S2 in ESI $\dagger$ ) and frozen (77 K) solutions (Fig. S5 and Table S2 in ESI $\dagger$ ). However, the magnitudes of each particular energy shift are not exactly the 

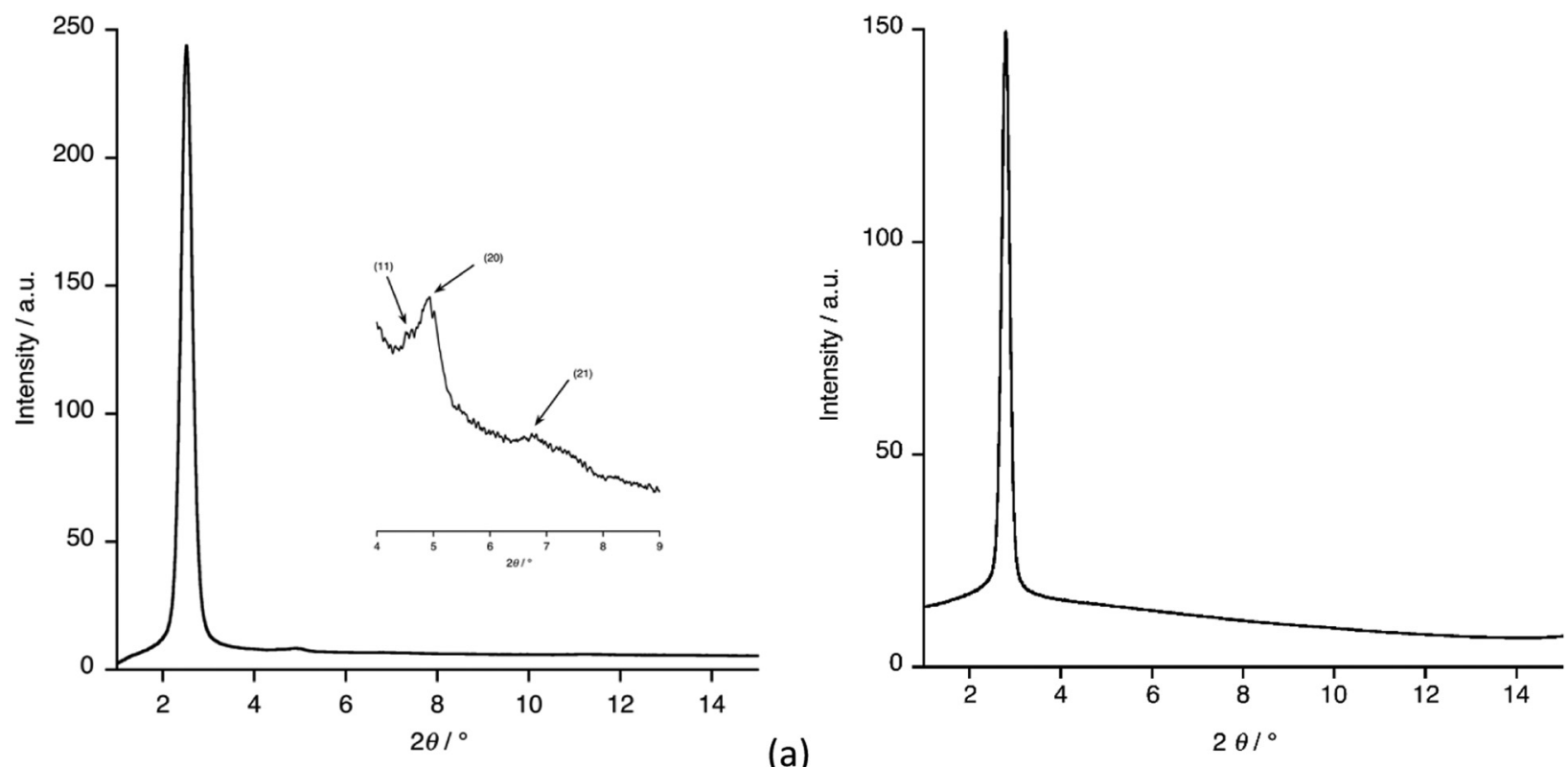

(a)

(b)

Fig. 2 SAXS patterns for: (a) compound $3 \mathbf{b}$ at $39.4{ }^{\circ} \mathrm{C}$; (b) compound $\mathbf{4 b}$ at $45.5^{\circ} \mathrm{C}$.

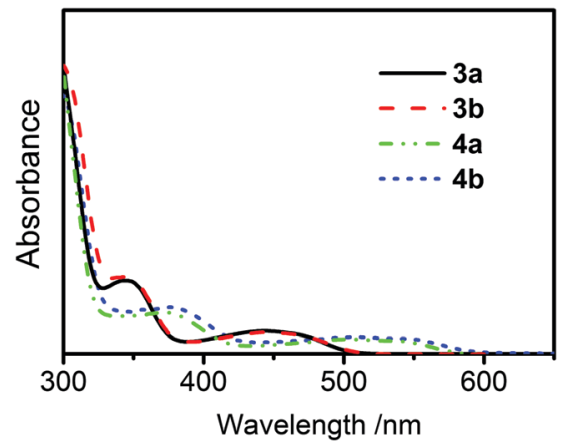

Fig. 3 UV-Vis absorption spectra of compounds $3 a, 3 b, 4 a$ and $4 b$ in toluene.

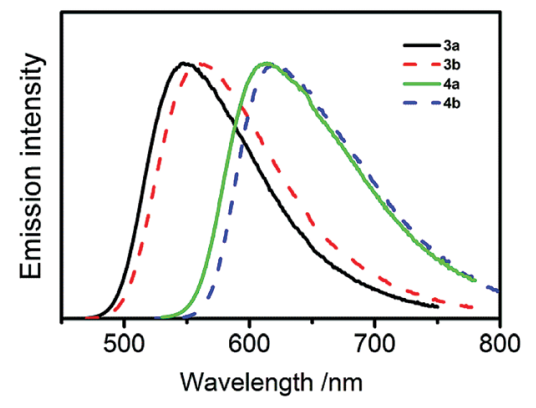

Fig. 4 Luminescence spectra of compounds $3 a, 3 b, 4 a$, and $4 b$ recorded in degassed diluted toluene solutions (ca $5 \times 10^{-5} \mathrm{~mol} \mathrm{dm}^{-3}$ ) at ambient temperature.

same, indicating that also other factors, such as local microenvironment, modulate excited state energies significantly.
Table 1 Luminescence properties determined in toluene solution at ambient temperature

\begin{tabular}{|c|c|c|c|c|c|c|}
\hline & $\begin{array}{l}\lambda_{\max } / \\
\mathrm{nm}\end{array}$ & $\begin{array}{l}\tau / \text { ns prompt } \\
\text { flu. }\end{array}$ & $\begin{array}{l}\tau / \mu \text { s delayed } \\
\mathrm{em} .\end{array}$ & $\phi_{\mathrm{PL}} / \%$ & $k_{\mathrm{r}} / \mathrm{s}^{-1}$ & $k_{\mathrm{nr}} / \mathrm{s}^{-1}$ \\
\hline $3 a$ & 545 & $12.2(9.9)^{b}$ & $5.5(10 \% \text { int })^{a}$ & $18(12)^{\text {air }}$ & $\begin{array}{l}1.3 \times 10^{7} \\
\left(1.2 \times 10^{7}\right)^{b}\end{array}$ & $\begin{array}{l}6.9 \times 10^{7} \\
\left(8.9 \times 10^{7}\right)^{b}\end{array}$ \\
\hline $3 \mathbf{b} 5$ & 560 & $6.9(6.4)^{b}$ & $3.5(5 \% \text { int })^{a}$ & 5 & $\begin{array}{l}0.6 \times 10^{7} \\
\left(0.8 \times 10^{7}\right)^{b}\end{array}$ & $\begin{array}{l}14 \times 10^{7} \\
\left(15 \times 10^{7}\right)^{b}\end{array}$ \\
\hline 4a & 615 & 3.9 & $\leq 1$ & 5 & $1.3 \times 10^{7}$ & $24 \times 10^{7}$ \\
\hline $4 \mathrm{~b}$ & 620 & 1.2 & $\leq 1$ & 1.5 & $1.3 \times 10^{7}$ & $82 \times 10^{7}$ \\
\hline
\end{tabular}

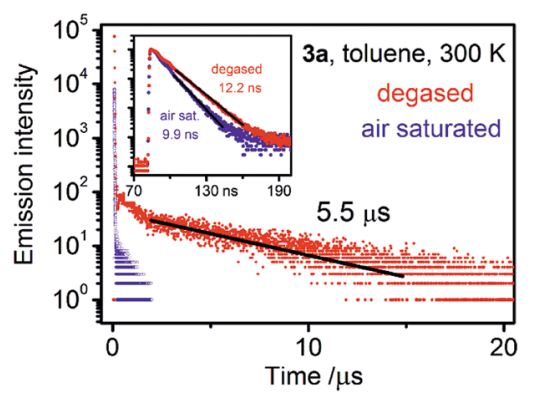

Fig. 5 Emission decay curves for compound 3a recorded in toluene at ambient temperature. Degassed and air saturated samples are compared.

The emissions recorded in liquid samples, with quantum yields from 1.5 to $18 \%$, are moderate, whereas those determined for solid samples are significantly higher with the maximum value of $30 \%$ found for compound 3a. (Table S1, ESI $\dagger$ ) This increase in quantum yield is a consequence of diminished non-radiative losses in a rigid microenvironments 
expressed by lower values of the non-radiative relaxation rate $k_{\mathrm{nr}}$ determined for solid samples (Table S1, ESI $\dagger$ ) when compared to solution (Table 1). The rates found for different compounds increase with decreasing energy of the emitting excited state, resembling the trend expected according to the energy gap law. ${ }^{20}$ For example, for liquid samples of $\mathbf{3 a}$ and $\mathbf{4 b}$, $k_{\mathrm{nr}}$ values of $6.9 \times 10^{7} \mathrm{~s}^{-1}$ and $82 \times 10^{7} \mathrm{~s}^{-1}$ are found, representing a difference by a factor of more than 10 . On the other hand, the radiative rate of prompt fluorescence $\left(k_{\mathrm{r}}\right.$ in Table 1 and Tables S1 and S2, ESI $\dagger$ ) is essentially invariant with compound composition and rigidity of the matrix.

\section{Theoretical studies}

To gain more insight into the luminescent properties of the materials, the electronic structure of the methoxy analogues 3b-Me, 4a-Me and 4b-Me was analysed theoretically. The computations utilised the Gaussian $09 \operatorname{code}^{21}$ with the M11L $\mathrm{L}^{22,23}$ density functional and def2-SVP basis set. ${ }^{24}$ Structures of 3b-Me, 4a-Me and 4b-Me were optimised in the ground state $\left(\mathrm{S}_{0}\right)$ and the lowest excited triplet state electronic configurations. The corresponding molecular geometries can be found in the format of Cartesian coordinates in the ESI. $\dagger$ The relaxed groundstate geometries calculated for $\mathbf{3 b} \mathbf{b}-\mathbf{M e}$ and $\mathbf{4 b}$-Me are comparable to those determined by X-ray analysis and, for example, the calculated interplanar angles between the mean planes of carbazoles and mean plane of the phenyl ring of terephthalonitrile $(\phi)$ are rather similar: (Expt./Calc.): 3b-Me $\left(54.84^{\circ} / 57.60^{\circ}\right)$; 4b-Me $\left(63.48^{\circ} / 65.97^{\circ}\right)$. The notably larger values of parameter $\phi$ in $\mathbf{4 a}-\mathbf{M e}$ and $\mathbf{4 b}-\mathbf{M e}$ compared to $\mathbf{3 b}-\mathbf{M e}$, is due to the greater degree of substitution, where planarisation of the molecule by rotation of the carbazole moieties is hampered by increased intramolecular steric hinderance.

According to the calculations, the lowest excited singlet $\left(\mathrm{S}_{1}\right)$ and triplet $\left(\mathrm{T}_{1}\right)$ states of $3 \mathbf{b}-\mathbf{M e}, \mathbf{4 a - M e}, \mathbf{4 b}-\mathbf{M e}$, are of HOMO $\rightarrow$ LUMO orbital origin. The HOMOs of these compounds represent $\pi$-orbitals localised predominantly on the carbazole units (donors) whereas the LUMO is a $\pi^{*}$ orbital localised predominantly on the terephthalonitrile (Fig. 6 and Tables S3-S6 in the ESI $\dagger$ ). Thus, transitions between the $S_{1}$ and $T_{1}$ states of $\mathbf{3 b}$-Me, $\mathbf{4 a}-\mathbf{M e}, \mathbf{4 b}-\mathbf{M e}$ can be described as $\pi \rightarrow \pi^{*}$ in character $\left({ }^{1,3} \pi \pi^{*}\right)$ with strong charge transfer $\left({ }^{1,3} \mathrm{CT}\right)$ from the donor carbazole to the acceptor terephthalonitrile. The unpaired electrons in these excited states are well separated spatially and have a weak exchange interaction resulting in a small triplet-singlet splitting $\Delta E\left(\mathrm{~S}_{1}-\mathrm{T}_{1}\right)$. The $\Delta E\left(\mathrm{~S}_{1}-\mathrm{T}_{1}\right)$ values, estimated from the energies of vertical (Frank-Condon) transitions $\mathrm{S}_{0} \rightarrow \mathrm{T}_{1}$ and $\mathrm{S}_{0} \rightarrow \mathrm{S}_{1}$ in the optimised $\mathrm{T}_{1}$ state geometries, are $0.05 \mathrm{eV}\left(400 \mathrm{~cm}^{-1}\right)$ for $3 \mathrm{~b}-\mathrm{Me}, 0.06 \mathrm{eV}\left(480 \mathrm{~cm}^{-1}\right)$ for $\mathbf{4 a - M e}$ and $0.04 \mathrm{eV}$ for $\mathbf{4 b}-\mathbf{M e}\left(320 \mathrm{~cm}^{-1}\right)$. These values are comparable to those of other donor-acceptor (D-A) organic materials designed to exhibit $\mathrm{TADF}^{25}$ and at ambient temperature should allow efficient thermal activation of the $T_{1}$ state to vibrational levels isoenergetic with the lower vibrational levels of the $\mathrm{S}_{1}$ state. (a)
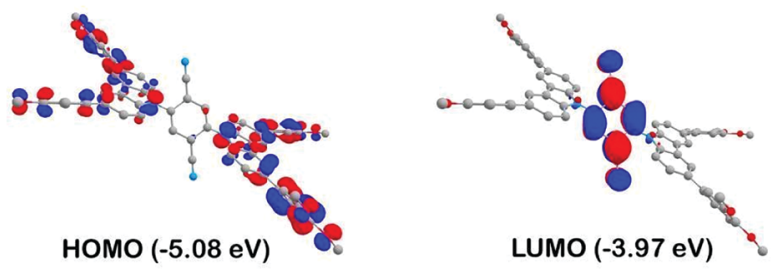

(b)
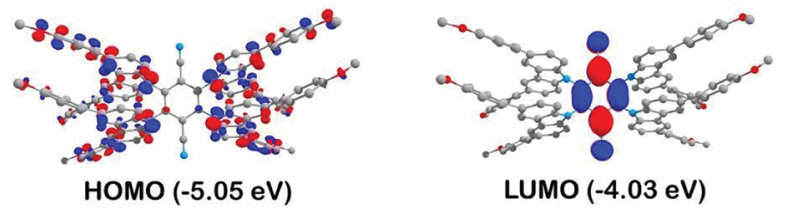

(c)
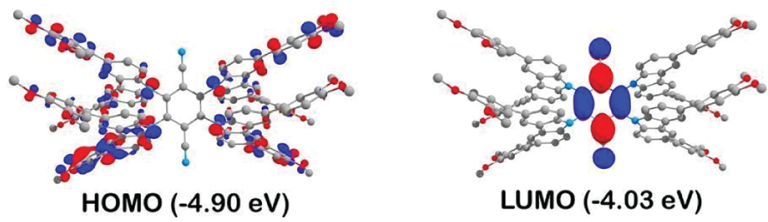

Fig. 6 The DFT (M11L/def2SVP) calculated iso-surface contour plots (iso-value $=0.03$ ) and energies of the frontier orbitals of $3 \mathrm{a}-\mathrm{Me}(\mathrm{a}), 4 \mathrm{a}-\mathrm{Me}$ (b) and $\mathbf{4 b - M e ~ ( c ) ~ i n ~ t h e ~} \mathrm{T}_{1}$ state optimised geometries. Hydrogens are omitted for clarity.

Intersystem crossing $\mathrm{S}_{1} \rightarrow \mathrm{T}_{1}$ (ISC) and reverse intersystem crossing $\mathrm{T}_{1} \rightarrow \mathrm{S}_{1}$ (RISC) are non-radiative transitions occurring between isoenergetic vibrational levels of states $S_{1}$ and $T_{1}$. The rates of these transitions determine the efficiency of thermal equilibration of $S_{1}$ and $T_{1}$, which is essential for TADF to occur. The rates of transition where a change in multiplicity is involved (e.g. singlet $\leftrightarrow$ triplet) is determined by the efficiency of the spin-flip of an unpaired electron during the transition and is efficient only with conservation of the total momentum of the electron (spin plus orbital-El-Sayed's rule ${ }^{26}$ ). In organic molecules, the main mechanism facilitating this conservation is spin-orbit coupling (SOC). ${ }^{27}$ For the $\mathrm{S}_{1}$ and $\mathrm{T}_{1}$ states of $\mathbf{3 b}$ Me, $4 \mathrm{a}-\mathrm{Me}$ and $4 \mathrm{~b}-\mathrm{Be},{ }^{1} \pi \pi^{*} \leftrightarrow{ }^{3} \pi \pi^{*}$ ISC and ${ }^{3} \pi \pi^{*} \rightarrow{ }^{1} \pi \pi^{*}$ RISC processes are spin-forbidden in the zeroth-order approximation. The forbidden nature in this approximation can, however, be relaxed with perturbations caused by molecular vibrations. These can induce vibronic and spin-orbit coupling of the $S_{1}$ and $T_{1}$ states with $\pi \pi^{*}$ states resulting from local excitations at the carbazole unit and at the terephthalonotrile $\left({ }^{3} \mathrm{LE}\right.$ triplets) as well as with $\sigma \pi^{*}$ and $\pi \sigma^{*}$ states. ${ }^{28}$ For instance, the vibrations displacing the atoms out of the plane of $\pi$-conjugation electronically perturb the $S_{1}$ state (charge transfer ${ }^{1} \pi \pi^{*}$ ) admixing it with singlet states of ${ }^{1} \sigma \pi^{*}$ and ${ }^{1} \pi \sigma^{*}$ character (vibronic coupling), giving a non-vanishing SOC matrix element with a triplet state having (at least partial) ${ }^{3} \pi \pi^{*}$ character. Also, SOC of the $\mathrm{S}_{1}$ state with triplet states of ${ }^{3} \sigma \pi^{*}$ and ${ }^{3} \pi \sigma^{*}$ character or with ${ }^{3} \pi \pi^{*}$ character LE triplets, which may become close energetically to $\mathrm{S}_{1}$ during the molecular vibrations, relaxes the spin-forbidden nature of the $\mathrm{S}_{1} \leftrightarrow \mathrm{T}_{1}$ transition. Similarly, the $T_{1}$ state is perturbed by vibronic coupling to other 
triplet states and by SOC with electronically suitable singlet states. Therefore, the perturbed $S_{1}$ and $T_{1}$ states can have a non-vanishing SOC matrix element relaxing the otherwise forbidden zeroth-order ISC and RISC processes between them. It is noted that this relaxation is weak due to the comparatively large energy gap to the perturbing (admixing) states ( $\sigma \pi^{*}, \pi \sigma^{*}$ and LE $\pi \pi^{*}$ states) and small spin-orbit coupling constants of the light elements $(\mathrm{H}, \mathrm{C}, \mathrm{N})^{29}$ constituting 3b-Me, 4a-Me and 4b-Me.

Since the molecular vibrations facilitate the $S_{1} \leftrightarrow T_{1}$ transition rates, it can be expected that ISC and RISC rates in 4a-Me and $\mathbf{4 b}$-Me are larger compared to $3 \mathbf{b}-\mathbf{M e}$. This is due to the structural design of $\mathbf{4 a - M e}$ and $\mathbf{4 b}-\mathbf{M e}$ with four carbazole derivatives affording much larger number of vibrational modes of the molecule $(3 N-6)$ compared to $3 \mathbf{b}$-Me with only two carbazole units. Therefore, in $\mathbf{4 a - M e}$ and $\mathbf{4 b}-\mathbf{M e}$, the thermal equilibration of the $S_{1}$ and $T_{1}$ states is more efficient than in 3a-Me. It is noted, however, that $S_{1} \rightarrow T_{1}$ ISC and $T_{1} \rightarrow S_{1}$ RISC processes compete with the direct relaxation processes (radiative and non-radiative) to the ground state, $\mathrm{S}_{1} \rightarrow \mathrm{S}_{0}$ and $\mathrm{T}_{1} \rightarrow \mathrm{S}_{0}$, respectively. This may be important in comparing the photophysical properties of $\mathbf{4 a - M e}$ and $4 \mathbf{b}-\mathbf{M e}$. Thus, with double the number of alkoxy $\pi$-donors on the carbazole unit of $\mathbf{4 b}-\mathbf{M e}$, its HOMO is higher in energy, which in turn results in lower energies of the $\mathrm{S}_{1}$ and $\mathrm{T}_{1}$ excited states (HOMO $\rightarrow$ LUMO), compared to 4a-Me. According to the energy gap law, ${ }^{20,30}$ a decrease in the energy of an excited state facilitates exponential increase of non-radiative relaxation rates to the ground state. Therefore, the $\mathrm{T}_{1} \rightarrow \mathrm{S}_{0}$ non-radiative decay in 4b-Me is probably faster than in $\mathbf{4 a - M e , ~ w h i c h ~ m a y ~ c o m p r o m i s e ~}$ the efficiency of competing $\mathrm{T}_{1} \rightarrow \mathrm{S}_{1}$ RISC and, consequently, the efficiency of TADF.

\section{Conclusions}

Carbazole-substituted terephthalonitriles, functionalised on the periphery by alkoxy chains, have been prepared and studied in detail for their liquid-crystalline and photophysical properties, the latter underpinned by calculation. The challenge of generating an anisotropic molecule from a rather three-dimensional core necessitated the use of multiple peripheral chains; the synthetic chemistry dictated that these were attached as alkoxy chains. The consequence of using such good donors and in number is to red-shift emission and consequently to diminish the emission efficiency. Interestingly, the data show that the number of methoxy groups used affects the emission efficiency independent of their position whereas the position of the methoxy groups matters in relation to the degree of bathochromism in the emission. Clearly there are design criteria that emerge from this initial study that will inform future approaches, but this does not diminish the realisation of multifunctional materials with both liquid crystal and TADF properties.

\section{Conflicts of interest}

There are no conflicts of interest to declare.

\section{Acknowledgements}

The authors would like to thank the University of York (AFS), the Universität Regensburg (MZS) and the German Research Foundation (DFG) (Project No. 389797483) for financial support.

\section{References}

1 M. O'Neill and S. M. Kelly, Adv. Mater., 2011, 23, 566-584.

2 A. Diez, S. J. Cowling and D. W. Bruce, Chem. Commun., 2012, 48, 10298-10300.

3 H. Iino, T. Usui and J.-i. Hanna, Nat. Commun., 2015, 6, 6828.

4 S. Allard, M. Förster, B. Souharce, H. Thiem and U. Scherf, Angew. Chem., Int. Ed., 2008, 47, 4070-4098.

5 M. Kumar and S. Kumar, Polym. J., 2017, 49, 85-111.

6 E. Grelet, H. Bock, T. Brunet, J. Kelber, O. Thiebaut, P. Jolinat, S. Mirzaei and P. Destruel, Mol. Cryst. Liq. Cryst., 2011, 542, 182-189.

7 Y. Wang, J. Shi, J. Chen, W. Zhu and E. Baranoff, J. Mater. Chem. C, 2015, 3, 7993-8005.

8 S. Kappaun, C. Slugove and E. J. W. List, Int. J. Mol. Sci., 2008, 9, 1527-1547.

9 H.-H. Kuo, Z.-l. Zhu, C.-S. Lee, Y.-K. Chen, S.-H. Liu, P.-T. Chou, A. K. Y. Jen and Y. Chi, Adv. Sci., 2018, 5, 1800846.

10 M. Y. Wong and E. Zysman-Colman, Adv. Mater., 2017, 29, 1605444.

11 H. Uoyama, K. Goushi, K. Shizu, H. Nomura and C. Adachi, Nature, 2012, 492, 234-238.

12 A.-M. Giroud-Godquin and A. Rassat, C. R. Seances Acad. Sci., Ser. 2, 1982, 294, 241-243.

13 A. Serrette, P. J. Carroll and T. M. Swager, J. Am. Chem. Soc., 1992, 114, 1887-1889.

14 A. G. Serrette and T. M. Swager, J. Am. Chem. Soc., 1993, 115, 8879-8880.

15 A. M. Prokhorov, A. Santoro, J. A. G. Williams and D. W. Bruce, Angew. Chem., Int. Ed., 2012, 51, 95-98.

16 A. Santoro, A. M. Prokhorov, V. N. Kozhevnikov, A. C. Whitwood, B. Donnio, J. A. G. Williams and D. W. Bruce, J. Am. Chem. Soc., 2011, 133, 5248-5251.

17 T. Chuard and R. Deschenaux, Helv. Chim. Acta, 1996, 79, 736-741.

18 M. K. Etherington, N. A. Kukhta, H. F. Higginbotham, A. Danos, A. N. Bismillah, D. R. Graves, P. R. McGonigal, N. Haase, A. Morherr, A. S. Batsanov, C. Pflumm, V. Bhalla, M. R. Bryce and A. P. Monkman, J. Phys. Chem. C, 2019, 123, 11109-11117.

19 B. Donnio, B. Heinrich, H. Allouchi, J. Kain, S. Diele, D. Guillon and D. W. Bruce, J. Am. Chem. Soc., 2004, 126, 15258-15268.

20 R. Englman and J. Jortner, Mol. Phys., 1970, 18, 145-164.

21 M. J. Frisch, G. W. Trucks, H. B. Schlegel, G. E. Scuseria, M. A. Robb, J. R. Cheeseman, G. Scalmani, V. Barone, B. Mennucci, G. A. Petersson, H. Nakatsuji, M. Caricato, X. Li, H. P. Hratchian, A. F. Izmaylov, J. Bloino, G. Zheng, 
J. L. Sonnenberg, M. Hada, M. Ehara, K. Toyota, R. Fukuda, J. Hasegawa, M. Ishida, T. Nakajima, Y. Honda, O. Kitao, H. Nakai, T. Vreven, J. A. Montgomery Jr., J. E. Peralta, F. Ogliaro, M. J. Bearpark, J. Heyd, E. N. Brothers, K. N. Kudin, V. N. Staroverov, R. Kobayashi, J. Normand, K. Raghavachari, A. P. Rendell, J. C. Burant, S. S. Iyengar, J. Tomasi, M. Cossi, N. Rega, N. J. Millam, M. Klene, J. E. Knox, J. B. Cross, V. Bakken, C. Adamo, J. Jaramillo, R. Gomperts, R. E. Stratmann, O. Yazyev, A. J. Austin, R. Cammi, C. Pomelli, J. W. Ochterski, R. L. Martin, K. Morokuma, V. G. Zakrzewski, G. A. Voth, P. Salvador, J. J. Dannenberg, S. Dapprich, A. D. Daniels, Ö. Farkas, J. B. Foresman, J. V. Ortiz, J. Cioslowski and D. J. Fox, Gaussian 09, Gaussian, Inc., Wallingford, CT, USA, 2009.

22 R. Peverati and D. G. Truhlar, J. Phys. Chem. Lett., 2012, 3, 117-124.
23 R. Peverati and D. G. Truhlar, Phys. Chem. Chem. Phys., 2012, 14, 11363-11370.

24 F. Weigend, Phys. Chem. Chem. Phys., 2006, 8, 1057-1065.

25 A. Endo, K. Sato, K. Yoshimura, T. Kai, A. Kawada, H. Miyazaki and C. Adachi, Appl. Phys. Lett., 2011, 98, 083302.

26 M. A. El-Sayed, J. Chem. Phys., 1963, 38, 2834-2838.

27 N. J. Turro, V. Ramamurthy and J. C. Scaiano, Modern Molecular Photochemistry of Organic Molecules, University Science Books, Saisalito, 2010, pp. 149-156.

28 B. R. Henry and W. Siebrand, J. Chem. Phys., 1971, 54, 1072-1085.

29 M. Montalti, A. Credi, L. Prodi and M. T. Gandolfi, Handbook of Photochemistry, CRC Press, 3rd edn, 2006.

30 J. V. Caspar and T. J. Meyer, J. Phys. Chem., 1983, 87, 952-957. 